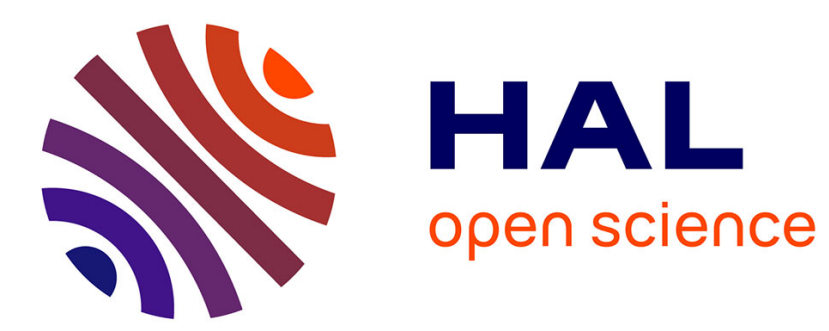

\title{
A medico-economic study of trabectedin compared with end-stage treatment in soft tissue sarcomas
}

Johanne Daupin, Pascal Paubel, Daniele Grazziotin-Soares, Jean-Pierre Lotz

\section{To cite this version:}

Johanne Daupin, Pascal Paubel, Daniele Grazziotin-Soares, Jean-Pierre Lotz. A medico-economic study of trabectedin compared with end-stage treatment in soft tissue sarcomas. Journal of Cancer Policy, 2017, 12, pp.55 - 60. 10.1016/j.jcpo.2017.03.011 . hal-01501359

\section{HAL Id: hal-01501359 \\ https://hal.sorbonne-universite.fr/hal-01501359}

Submitted on 4 Apr 2017

HAL is a multi-disciplinary open access archive for the deposit and dissemination of scientific research documents, whether they are published or not. The documents may come from teaching and research institutions in France or abroad, or from public or private research centers.
L'archive ouverte pluridisciplinaire HAL, est destinée au dépôt et à la diffusion de documents scientifiques de niveau recherche, publiés ou non, émanant des établissements d'enseignement et de recherche français ou étrangers, des laboratoires publics ou privés. 
A medico-economic study of trabectedin compared with end-stage treatment in soft tissue sarcomas

Johanne Daupin $^{\mathrm{a}, \mathrm{b}}$, Pascal Paubel ${ }^{\mathrm{b}, \mathrm{c}}$, Daniele G. Soares ${ }^{\mathrm{d}}$, Jean-Pierre Lotz ${ }^{\mathrm{d}, \mathrm{e}}$

a- Department of Pharmacy, Hospital Tenon (Hôpitaux Universitaires de l'Est-Parisien, APHP), 4 rue de la Chine, 75020 Paris, France

b- Faculty of Pharmacy, University Paris Descartes (Université Paris 05) \& Institut Droit et Santé, INSERM UMR S 1145, 12 Rue de l'École de Médecine, 75006 Paris, France

c- General Agency for Equipment and Health Products (Hôpitaux Universitaires de l'EstParisien, AP-HP), 4 rue de la Chine, 75020 Paris, France

d- Department of Medical Oncology and Cellular Therapy, APREC (Alliance Pour la Recherche En Cancérologie), Hospital Tenon (Hôpitaux Universitaires de l'Est-Parisien, AP-HP), 4 rue de la Chine, 75020, Paris, France

e- Sorbonne Universities, University Pierre \& Marie Curie (UPMC Université Paris 06), 4 Place Jussieu, 75005, Paris, France

\section{Corresponding Author:}

Professor Jean-Pierre Lotz

Medical Oncology and Cellular Therapy Department, Hôpital Tenon, Assistance Publique-Hôpitaux de Paris (AP-HP), APREC; 4 rue de la Chine, 75970 Paris Cedex 20, France.

Tel: +33156016058

Fax: +33156016875

E-mail: jean-pierre.lotz@aphp.fr

\section{Highlights}


- Trabectedin is indicated to treat advanced soft-tissue sarcomas

- Data from sarcoma patients treated with trabectedin were retrospectively analyzed

- This was a medico-economic study to evaluate the cost-effectiveness of trabectedin

- Trabectedin was compared with end-stage treatment

- Trabectedin was considered cost-effective in the context of an orphan disease

\section{ABSTRACT}

The development of new anticancer drugs has strongly contributed to improve patients' outcomes. However, the question can be raised whether the sometimes minor benefits are worth the cost to both the individuals and the society. The aim of this medico-economic study was to evaluate trabectedin cost-effectiveness compared with end-stage care in the treatment of soft-tissue sarcoma. We retrospectively analysed data from 45 patients treated with trabectedin for soft tissue sarcoma. Real-life data of clinical benefits and costs of trabectedin were compared with simulated end-stage treatment. Univariate and probabilistic sensitivity analyses identified key drivers of the incremental cost-effectiveness ratio. Trabectedin was associated with longer progression-free survival (4.0 months versus 1.6 months) and higher costs $(€ 24,780$ versus $€ 15,490)$ compared with end-stage treatment. The incremental cost per year of progression-free survival gained with trabectedin was $€ 46,104$ (95\% confidence interval; €45,039 - €47,169). The results were relatively insensitive to changes. Trabectedin was cost-effective in the context of an orphan disease, when used to treat patients with a short life expectancy and few therapeutic options.

Keywords: trabectedin, soft-tissue-sarcoma, economic, cost-effectiveness

Classification codes: pharmacoeconomic, medical care, medico economic, health 


\section{INTRODUCTION}

Trabectedin is a marine-derived antineoplastic drug isolated from the Caribbean organism Ecteinascidia turbinata and currently produced synthetically. It is indicated for the treatment of unresectable or metastatic soft tissue sarcomas (STS) that have failed a prior anthracyclinecontaining regimen. The prognostic of progression-free survival (PFS) and overall survival (OS) for patients who relapse after first-line rarely exceed 6 months or 1 year $[1,2]$. Before the approval of trabectedin in Europe in 2007, a few agents have shown promising results when given as secondline treatment $[3,4]$. The antitumor activity of trabectedin has been demonstrated in several preclinical models and in clinical trials [5-8]. The clinical studies have provided data of efficacy for its marketing authorization [9] and have confirmed the clinical benefits of the drug when used in STS [10].

Because cancer drugs are used to treat patients with generally incurable diseases, new drugs have been rapidly adopted. The cost of new cancer treatments has however rarely been questioned. Today, high costs may prove a key limitation for accessibility. Indeed, health care in general and cancer care in particular can be expensive. While outcomes have improved in many areas due to new cancer treatments and technologies, the question can be raised whether the sometimes minor benefits are worth the cost to both the individuals and the society.

Regarding trabectedin, limited number of data is available on its use in routine clinical practice [1113] or on its cost-effectiveness [14]. The aim of this study was to assess the cost-effectiveness of trabectedin against end-stage treatment (EST) when trabectedin was used in daily clinical practice to treat non-selected patients who were, for most of them, not eligible for inclusion in clinical trials. To do that, we conducted a retrospective analysis of data from STS patients treated in our institution from 2005 to 2014 .

\section{METHODS}




\section{Model structure}

The study population comprised adult patients with advanced STS, previously treated with CT. Because current evidence does not support any other second-line of CT for advanced STS, trabectedin treatment (24-h infusion every 21 days) was compared with EST (ie palliative medicine and care) initiated after the later line of CT.

A simplified schematic picture of the model structure is presented in Figure 1. The model started with the failure of a previous CT for the treatment of advanced STS. The two alternatives are trabectedin or EST. In this model, patients could present 4 health states: remission, stable disease (SD), progressive disease (PD) and death. Patients on trabectedin could have a treatment response (remission or SD), disease progression or they could die. Patients on EST stayed in PD until death.

\section{Effectiveness data}

To assess trabectedin effectiveness, medical records of all patients with STS, having received trabectedin between January 2005 and May 2014, in Tenon hospital, Paris, were analyzed retrospectively until the cut-off date of August $1^{\text {st }}$ 2014. The end-point of trabectedin effectiveness was progression-free survival (PFS). The durations of PFS was calculated according to the KaplanMeier method, from the date of inclusion to the date of progression or the most recent evaluation.

Effectiveness in the EST arm was estimated according to data published in the literature. Results of efficacy obtained in the placebo arm of a phase III trial of pazopanib versus placebo, conducted in patients with STS [15], were used to estimate the effectiveness of EST in our study.

\section{Resources uses and costs}

This medico-economic study was performed from the healthcare payer perspective. All pricing data used were based on regulated tariffs in the French Healthcare system. Drugs and biological 
analyses' prices corresponded to tariffs established by the French public health insurance applicable in 2014. Hospitalization costs were based on the French reimbursement tariff in 2014, according to the diagnosis-related group (DRG) in the French Agency for Information on Hospital Care $(\mathrm{AlHC})$ classification, version $11 \mathrm{f}[16]$. Pricing data of patients' transportations came from a report made in 2012 by the National Audit Office in France [17].

Concerning the cost of the trabectedin treatment strategy it included the cost of the drug itself, the cost of the inpatient administrations (at least one-day hospitalization is needed for the infusion of trabectedin), the cost of patients' transportations from and to hospital, the cost of drugs prescribed to prevent trabectedin-related adverse events (AEs), the cost of the biological follow-up between two cycles of trabectedin and the cost of hospitalizations to manage its related AEs. All costs related to trabectedin were collected from data of our cohort in clinical practice and regarding the French health care payer perspective.

In the trabectedin arm, all hospital stays in our cohort during the treatment were extracted from Tenon hospital's database and were linked to a reimbursement price by using the French classification of the Diagnosis-Related Group (DRG). DRGs were homogeneous units of hospital activity to which binding prices could be attached.

The cost of the EST strategy was estimated by the cost of stays in palliative care unit or home cares settings for the public French healthcare system. Considering the poor prognosis and rapid disease progression of patients with advanced STS, we supposed that these patients after failure of previous CT were treated for the end-stage in palliative care unit or in home care settings. Data needed for this estimation were obtained from the classification of DRG in the specific units. No costs for treating any AEs were applied in the EST arm and no costs related to death were assumed.

\section{Outcomes measures and sensitivity analysis}

The results are presented as incremental cost-effectiveness ratio (ICER). ICER is defined as: ICER $=\Delta \mathrm{C} / \Delta \mathrm{E}=(\mathrm{C} 1-\mathrm{C} 0) /(\mathrm{E} 1-\mathrm{E} 0)$ 
Where $\mathrm{C}$ stands for average costs and $\mathrm{E}$ for average health benefits (subscripts indicate treatment; 1 is trabectedin and 0 is EST). ICER characterizes the marginal value of treatments in the form of additional cost per additional unit of health gained or saved during given perspective. In this study, ICER is produced for months of PFS gained in a lifelong perspective. The probability of costeffectiveness was assessed with the cost-effectiveness acceptability frontier (CEAF).

\section{Sensitivity analysis}

To identify key model drivers, all inputs were subject to univariate sensitivity analyses, except clinical parameters providing from our cohort's data. Unit cost values of drugs, laboratory tests, transportation and hospitalizations in palliative care or home settings were varied above or below 20 percent.

In addition, the following scenarios were simulated: (a) patient with EST in palliative care or home setting experienced a re-admission in hospital oncology unit; (b) average body surface area of $1.5 \mathrm{~m}^{2}$ and $2.0 \mathrm{~m}^{2}$; (c) treatment of chemotherapy induced nausea and vomiting including or not aprepitant; (d) $50 \%$ or $100 \%$ of patients with EST received blood transfusion; (e) $25 \%$ or $75 \%$ of patients with EST received drainage of pleural effusion; (f) trabectedin serious AEs costs doubled.

A probabilistic sensitivity analysis was also conducted. The mean ICERs and its confidence interval (Cl) of 95\% were estimated from 10000 probabilistic simulation results of boostrapping.

\section{RESULTS}

\section{Effectiveness and costs}

Between January 2005 and May 2014, trabectedin was given to 45 STS patients as a 24-hour continuous intravenous infusion, every 3 weeks in our French institution. After a median follow-up 
of 31.5 months (ranging from 5.6 to 110 months), median PFS was 4.0 months ( $95 \% \mathrm{CI}, 1.6 ; 6.4)$ (Figure 2).

The cohort treated with trabectedin experienced a total of 264 stays in hospitalization, including 227 for the trabectedin administration and 21 stays to treat trabectedin-related AEs. All these hospitalizations amount to 370819 euros, i.e. 8240 euros per patient.

In our cohort, the average trabectedin dose intensity was $1.35 \mathrm{mg} / \mathrm{m}^{2}$ and the average body surface area (BSA) was $1.80 \mathrm{~m}^{2}$, which results in $2.43 \mathrm{mg}$ per administration (BSA of $1.50 \mathrm{~m}^{2}$ and $2.00 \mathrm{~m}^{2}$ were assumed in a sensitivity analysis scenario). Given the trabectedin vials size, patients were conservatively assumed to receive two $1-\mathrm{mg}$ vials and two $0.25-\mathrm{mg}$ vials per administration.

The 45 patients of the cohort received a total of 244 cycles of trabectedin, which results in 5.4 cycles per patient. Average drug cost based on the average of 5 cycles was applied to the entire cohort, which constitutes the trabectedin arm in the model.

Effectiveness in the EST arm was estimated according to the clinical study [15] which showed that patients with advanced STS who received placebo reached a median PFS of 1.6 months. The costs of these 48 days in palliative home care settings were translated to the public French Health care system. These costs depend on patients' performance status estimated by Karnofski scoring. According to experts' opinion, patients with metastatic STS after failure of the initial treatment reached a maximum Karnofski score of $50 \%$. The impacts of these EST assumptions were tested in sensitivity analysis. Table 1 summarizes the base-case results for cost-effectiveness of trabectedin versus EST in advanced STS.

\section{Cost-effectiveness}

The use of trabectedin in metastatic STS patients was associated with a gain of 0.20 progressionfree life-years and $€ 9,290$ higher costs compared with EST in patients with advanced STS after failure of standard first-line chemotherapy. Total of incremental costs for trabectedin compared EST 
were estimated to be $€ 46,449$ per progression-free life-year from the health care system perspective (Table1).

\section{Sensitivity analysis}

Overall, more than 50 sensitivity analyses were conducted. The cost-effectiveness of trabectedin versus EST was insensitive to variations in the assumptions made. An illustrative tornado plot for sensitive parameters is shown in Figure 3. After 1000 probabilistic simulations generated by bootstrapping, the probabilistic sensitivity analysis estimated a mean ICER of $€ 46,104(\mathrm{Cl} 95 \%$ $€ 45,039$ - €47,169).

\section{Conclusion}

This study explored health benefits and costs of trabectedin in clinical practice, compared with EST, in the treatment of patients with advanced STS.

The results show that treatment with trabectedin was associated with higher PFS than EST (4.0 months versus 1.6 months), but also with higher costs (€24,780 versus $€ 15,490$ in the EST arm). The incremental cost per progression-free life-years gained was superior in our cohort than in the work by Soini [14] $(€ 46,104$ versus $€ 31,590)$. The use of trial-based data in previous study could explain this difference in term of costs. Indeed, extrapolating trails data to a real-life scenario induce a selection bias. Our results show that trabectedin when given in real-life practice seems to generate more costs than in clinical trials. For example, in our cohort, costs of hospitalizations for trabectedinrelated AEs were 3.5 time higher than in the clinical trial (respectively an average of $€ 277.65$ per trabectedin cycle versus $€ 79.50$ per cycle in ET743-STS-201 study). The poorer baseline health status of our patients may have impacted patients' tolerance to trabectedin and induced more difficulties to manage trabectedin-related AEs.

The sensitivity analysis identified several factors as drivers of cost-effectiveness' results. These factors included costs of stays in palliative care unit or home settings, costs of trabectedin 
administration, administered dose and price of trabectedin, costs of neutropenia prevention with hematopoietic growth factor and costs to manage trabectedin-related serious AEs. Based on these results, a great cost saving could be occurred with trabectedin administration as outpatient with infusion pumps. In addition, ambulatory infusion pumps could be an option to improve patients' comfort and quality of life. Preventing AEs that lead to hospitalization could also have a great positive impact on trabectedin cost-effectiveness ratio. By contrast, the impact of laboratory tests, ambulatory antiemetic treatment and transportation on trabectedin cost-effectiveness was limited.

To determine whether trabectedin is cost-effective or not, there is no established cost-effectiveness threshold in the French healthcare system. In United Kingdom, the National Institute for Health and Clinical Excellence (NICE) has established a willingness to pay of $£ 30,000$ per Quality Adjusted Life-Year (QALY), i.e approximately $€ 44,000$ per QALY. Since 2009, the NICE decided to give special additional weight to health gains from life-extending end-of-life treatments. For end of life care in patients with a short life expectancy (less than 24 months) and no other therapeutic option, the cost-effectiveness threshold has been raised to $£ 70,000$, i.e $€ 100,000$, if more than 3 months of life should be gained with the assessed end of life care [18-21]. This was a response to mounting concern from NICE's stakeholders that effective new drugs for end-stage cancer often fail NICE's standard test of cost effectiveness [19-21]. Trabectedin fit the NICE's definition of end-life care and the observed ICER in our study was inferior to the specific NICE's threshold.

Like any economic evaluation, the current analyses encompassed a number of strengths and limitations. Although the observed PFS in our study was similar to those reported by clinical trials $[9,10]$, the retrospective nature of this study could overestimate the clinical benefits of trabectedin. Another study limitation is that calculated ICER does not include the quality of survival. Due to missing data we were not able to assess the quality of life in our patients.

Moreover, the main weakness of this study concerns the use of indirect data rather than head-tohead data for the EST arm. Indeed, the effectiveness of EST was estimated from the placebo arm of a phase III randomized trial of pazopanib in the treatment of advanced STS. 
According to the literature, several hypotheses have been made to estimate resources use of the EST arm and several pathways in palliative care unit or home settings have been simulated. STS is a rare cancer and it is common to used indirect comparisons of trials results in published literature on this disease $[14,22]$.

In conclusion, despite the observed ICER in our study higher than clinical trials, trabectedin seems to be cost-effective in the context of an orphan cancer, in patients with a short life expectancy and few therapeutic options.

\section{REFERENCES}

[1] A.T. van Oosterom, H.T. Mouridsen, O.S. Nielsen, P. Dombernowsky, K. Krzemieniecki, I. Judson, L. Svancarova, D. Spooner, C. Hermans, M. Van Glabbeke, J. Verweij; EORTC Soft Tissue and Bone Sarcoma Group. Results of randomised studies of the EORTC Soft Tissue and Bone Sarcoma Group (STBSG) with two different ifosfamide regimens in first- and second-line chemotherapy in advanced soft tissue sarcoma patients. Eur J Cancer 38(18) (2002): 2397-406.

[2] Nielsen, I. Judson, Q. van Hoesel, A. Le Cesne, H.J. Keizer, J.Y. Blay, A. van Oosterom, J.A. Radford, L. Svancárová, K. Krzemienlecki, C. Hermans, M. van Glabbeke, J.W. Oosterhuis, J. Verweij. Effect of high-dose ifosfamide in advanced soft tissue sarcomas. A multicentre phase II study of the EORTC Soft Tissue and Bone Sarcoma Group. Eur J Cancer 36(1) (2000): 61-7

[3] J.O. Bay, I. Ray-Coquard, J. Fayette, S. Leyvraz, S. Cherix, S. Piperno-Neumann, C. Chevreau, N. Isambert, E. Brain, G. Emile, A. Le Cesne, A. Cioffi, F. Kwiatkowski, J.M. Coindre, N.B. Bui, F. Peyrade, N. Penel, J.Y. Blay; Groupe Sarcome Français. Docetaxel 
and gemcitabine combination in 133 advanced soft-tissue sarcomas: a retrospective analysis. Int J Cancer 119(3) (2006): 706-11.

[4] M.L. Hensley, R. Maki, E. Venkatraman, G. Geller, M. Lovegren, C. Aghajanian, P. Sabbatini, W. Tong, R. Barakat, D.R. Spriggs. Gemcitabine and docetaxel in patients with unresectable leiomyosarcoma: results of a phase II trial. J Clin Oncol 20(12) (2002): 282431.

[5] M. D'Incalci, J. Jimeno. Preclinical and clinical results with the natural marine product ET-743. Expert Opin Investig Drugs 12(11) (2003): 1843-53.

[6] A. Le Cesne, J.Y. Blay, I. Judson, A. Van Oosterom, J. Verweij, J. Radford, P. Lorigan, S. Rodenhuis, I. Ray-Coquard, S. Bonvalot, F. Collin, J. Jimeno, E. Di Paola, M. Van Glabbeke, O.S. Nielsen. Phase II Study of ET-743 in Advanced Soft Tissue Sarcomas: A European Organisation for the Research and Treatment of Cancer (EORTC) Soft Tissue and Bone Sarcoma Group Trial. J Clin Oncol 23(3) (2004): 576-84.

[7] R. Garcia-Carbonero, J.G. Supko, J. Manola, M.V. Seiden, D. Harmon, D.P. Ryan, M.T. Quigley, P. Merriam, J. Canniff, G. Goss, U. Matulonis, R.G. Maki, T. Lopez, T.A. Puchalski, M.A. Sancho, J. Gomez, C. Guzman, J. Jimeno, G.D. Demetri. Phase II and pharmacokinetic study of ecteinascidin 743 in patients with progressive sarcomas of soft tissues refractory to chemotherapy. J Clin Oncol 22(8) (2004): 1480-90.

[8] A. Yovine, M. Riofrio, J.Y. Blay, E. Brain, J. Alexandre, C. Kahatt, A. Taamma, J. Jimeno, C. Martin, Y. Salhi, E. Cvitkovic, J.L. Misset. Phase II study of ecteinascidin-743 in advanced pretreated soft tissue sarcoma patients. J Clin Oncol 22(5) (2004): 890-9.

[9] G.D. Demetri, S.P. Chawla, M. von Mehren, P. Ritch, L.H. Baker, J.Y. Blay, K.R. Hande, M.L. Keohan, B.L. Samuels, S. Schuetze, C. Lebedinsky, Y.A. Elsayed, M.A. Izquierdo, J. Gómez, Y.C. Park, A. Le Cesne. Efficacy and safety of trabectedin in patients with advanced or metastatic liposarcoma or leiomyosarcoma after failure of prior 
anthracyclines and ifosfamide: results of a randomized phase II study of two different schedules. J Clin Oncol 27(25) (2009): 4188-96.

[10] G.D. Demetri, M. von Mehren, R.L. Jones, M.L. Hensley, S.M. Schuetze, A. Staddon, M. Milhem, A. Elias, K. Ganjoo, H. Tawbi, B.A. Van Tine, A. Spira, A. Dean, N.Z. Khokhar, Y.C. Park, R.E. Knoblauch, T.V. Parekh, R.G. Maki, S.R. Patel. Efficacy and Safety of trabectedin or dacarbazine for metastatic liposarcoma or leiomyosarcoma after failure of conventional chemotherapy: Results of a phase III randomized multicenter clinical trial. J Clin Oncol 34(8) (2016): 786-93.

[11] R. Roylance, B. Seddon, A. McTiernan, K. Sykes, S. Daniels, J. Whelan. Experience of the use of trabectedin (ET-743, Yondelis) in 21 patients with pre-treated advanced sarcoma from a single centre. Clin Oncol 19(8) (2007):572-6.

[12] J. Fayette, H. Boyle, S. Chabaud, B. Favier, C. Engel, P. Cassier, P. Thiesse, P. Méeus, M.P. Sunyach, G. Vaz, I. Ray-Coquard, D. Ranchère, A.V. Decouvelaere, L. Alberti, D. Pérol, J.Y. Blay. Efficacy of trabectedin for advanced sarcomas in clinical trials versus compassionate use programs: analysis of 92 patients treated in a single institution. Anticancer Drugs 21(1) (2010): 113-9.

[13] I. Gounaris, H.M. Hatcher, D. Davidson, K. Sherbourne, S. Alam, K.A. Zaki, G. Horan, H.M. Earl. Trabectedin for advanced soft tissue sarcomas: a single institution experience. Future Oncol 10(11) (2014): 1843-51.

[14] E.J. Soini, B. García San Andrés, T. Joensuu. Trabectedin in the treatment of metastatic soft tissue sarcoma: cost-effectiveness, cost-utility and value of information. Ann Oncol 22(1) (2011): 215-23.

[15] W.T. van der Graaf, J.Y. Blay, S.P. Chawla, D.W. Kim, B. Bui-Nguyen, P.G. Casali, P. Schöffski, M. Aglietta, A.P. Staddon, Y. Beppu, A. Le Cesne, H. Gelderblom, I.R. Judson, N. Araki, M. Ouali, S. Marreaud, R. Hodge, M.R. Dewji, C. Coens, G.D. Demetri, 
C.D. Fletcher, A.P. Dei Tos, P. Hohenberger; EORTC Soft Tissue and Bone Sarcoma Group; PALETTE study group. Pazopanib for metastatic soft-tissue sarcoma (PALETTE): a randomised, double-blind, placebo-controlled phase 3 trial. Lancet 379(9829) (2012): 1879-86.

[16] French Agency for Information on Hospital Care (AlHC), Classification of diagnosisrelated group version 11f. http://www.atih.sante.fr/regroupements-des-ghm-en-v11f, 2014 (accessed 2016/12/20).

[17] National Audit Office, Patients' transportations covered by the French public health insurance

https://www.ccomptes.fr/.../rapport securite sociale 2012 transports patients.pdf, 2012 (accessed 2016/20/12).

[18] K.K. Shah, A. Tsuchiya, A.J. Wailoo. Valuing health at the end of life: an empirical study of public preferences. Eur J Health Econ 15(4) (2014): 389-99.

[19] R. Cookson. Can the NICE "end-of-life premium" be given a coherent ethical justification? J Health Polit Policy Law 38(6) (2013): 1129-48.

[20] M. Collins, N. Latimer. NICE's end of life decision making scheme: impact on population health. BMJ (2013): 346-1363.

[21] J. Raftery. NICE and the challenge of cancer drugs. BMJ (2009): 338-67.

[22] T.E. Delea, J. Amdahl, H.R. Nakhaipour, S.C. Manson, A. Wang, N. Fedor, A. Chit. Cost-effectiveness of pazopanib in advanced soft-tissue sarcoma in Canada. Curr Oncol 21(6) (2014): e748-759. 
Figure 1. Model structure and health states. EST: End-Stage Treatment, PD: Progressive Disease, SD: Stable Disease

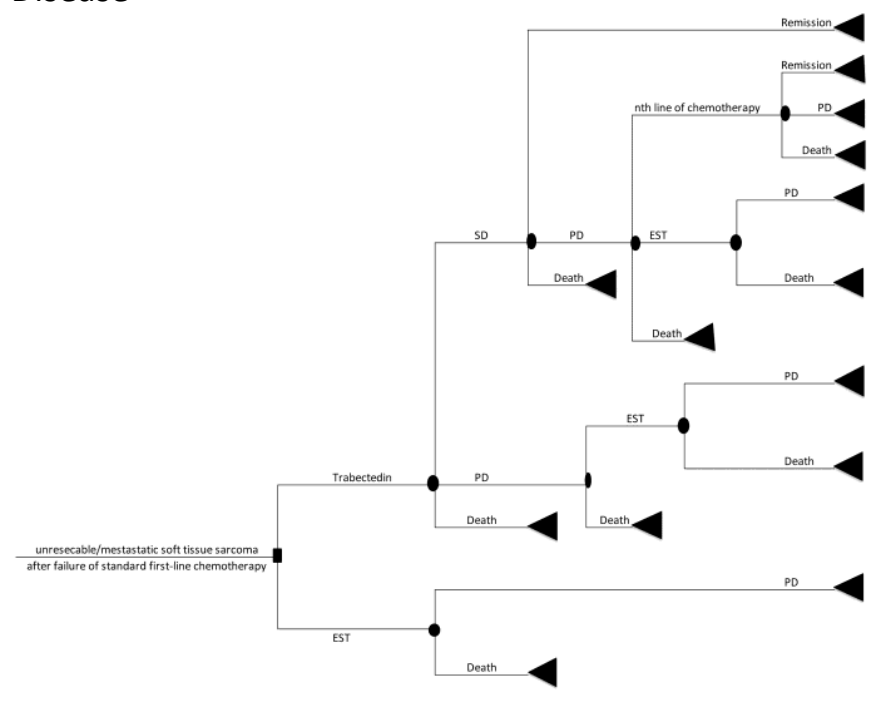

Figure 2. Kaplan-Meier plot of progression-free survival.

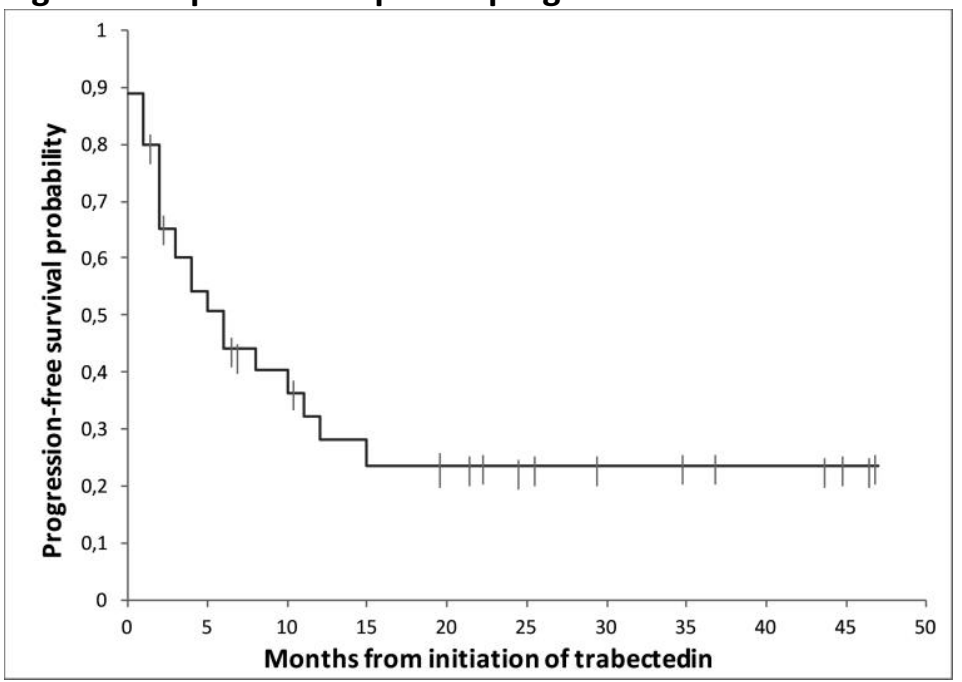

Figure 3. Tornado plots of cost-effectiveness of trabectedin versus end-stage treatment. AE: Adverse Event, BSA: Body Surface Area, G-CSF: Granulocyte-Colony Stimulating Factor, PFS: Progression-Free Survival, pts: patients, TRA: Trabectedin. 


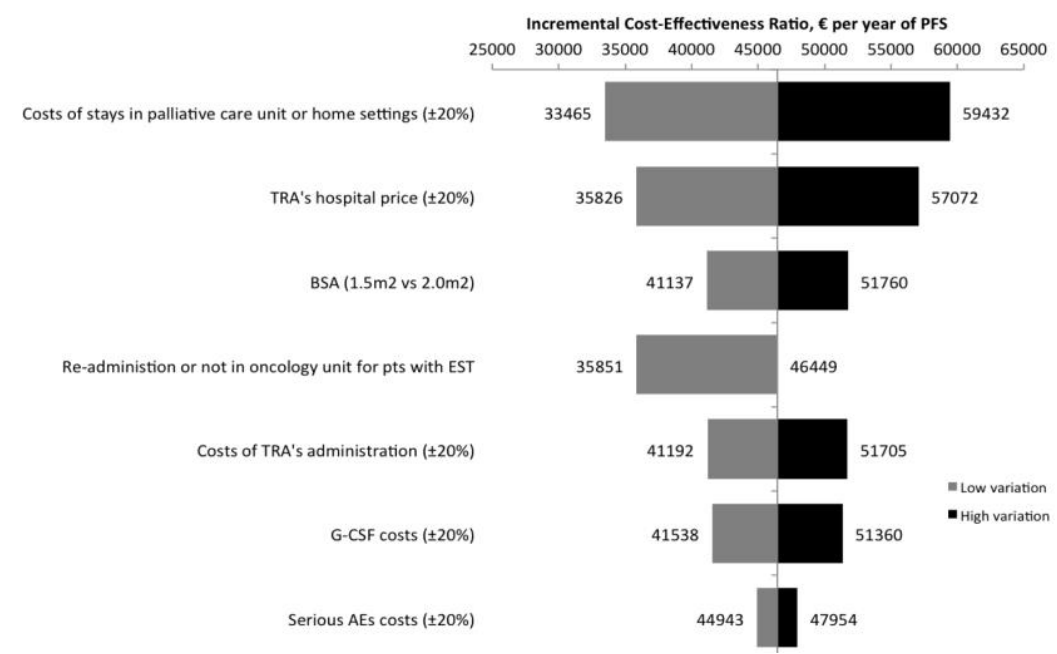


Table 1. Base-case results for cost-effectiveness of trabectedin versus EST in advanced STS.

\begin{tabular}{|c|c|c|c|c|c|c|c|}
\hline Inputs & \multicolumn{3}{|l|}{ TRA } & \multicolumn{3}{|l|}{ EST } & Incr. \\
\hline \multicolumn{8}{|l|}{ Effectiveness } \\
\hline PFS years & \multicolumn{3}{|l|}{0.33} & \multicolumn{3}{|l|}{0.13} & \\
\hline \multicolumn{8}{|c|}{ Costs $€$ (health care system perspective) } \\
\hline & Unit cost & $\begin{array}{l}\text { Units } \\
\text { /cycle }\end{array}$ & $\begin{array}{l}\text { Cost / } \\
\text { Patient }\end{array}$ & Unit cost & $\begin{array}{l}\text { Units / } \\
\text { Patient }\end{array}$ & $\begin{array}{l}\text { Cost / } \\
\text { Patient }\end{array}$ & \\
\hline \multicolumn{8}{|l|}{ Study medication } \\
\hline TRA 1mg & 849.84 & 2 & $8,498.40$ & - & - & - & \\
\hline TRA 0.25mg & 212.46 & 2 & $2,124.60$ & - & - & - & \\
\hline \multicolumn{8}{|c|}{ Adjuvant ambulatory medication } \\
\hline $\begin{array}{l}\text { Pegfilgrastim (G- } \\
\text { CSF) }\end{array}$ & 982.20 & 1 & $4,911.00$ & - & - & - & \\
\hline $\begin{array}{l}\text { Ondansetron } \\
\text { (antiemetic) }\end{array}$ & 17.15 & 1 & 85.75 & - & - & - & \\
\hline $\begin{array}{l}\text { Aprepitant } \\
\text { (antiemetic) }\end{array}$ & 47.19 & 1 & 235.95 & - & - & - & \\
\hline \multicolumn{8}{|l|}{ Hospitalizations } \\
\hline $\begin{array}{l}\text { TRA's } \\
\text { administration }\end{array}$ & * & 1 & $5,256.27$ & - & - & - & \\
\hline TRA's toxicity & * & & $1,505.49$ & - & - & - & \\
\hline $\begin{array}{l}\text { PC unit or home } \\
\text { settings }\end{array}$ & * & & $1,478.65$ & * & & $14,462.00$ & \\
\hline $\begin{array}{l}\text { Hepatic laboratory } \\
\text { tests }\end{array}$ & 18.90 & 3 & 283.50 & - & - & - & \\
\hline Transportation & 80.00 & 1 & 400.00 & 80.00 & 2 & 160.00 & \\
\hline $\begin{array}{l}\text { Blood transfusion in } \\
\text { day hospital }\end{array}$ & $\star *$ & & ** & 625.89 & 1 & 625.89 & \\
\hline $\begin{array}{l}\text { Drainage of pleural } \\
\text { effusion in day } \\
\text { hospital }\end{array}$ & ** & & $\star \star$ & 241.99 & 1 & 241.99 & \\
\hline Total Cost $€$ & $24,779.61$ & & & $15,489.88$ & & & $\begin{array}{l}9,289 . \\
73 \\
\end{array}$ \\
\hline $\begin{array}{ll}\text { ICER } & \text { (€/years } \\
\text { gained) } & \\
\end{array}$ & & & & & & & $\begin{array}{l}46,448 \\
.65 \\
\end{array}$ \\
\hline
\end{tabular}

* only costs per patient were reported

** included in costs of trabectedin toxicity

EST: end-stage treatment, G-CSF: granulocyte-colony stimulating factor, PC: palliative care unit, PFS: progression-free survival, TRA: trabectedin 